former days the bird-life appears, however, to have been even more abundant than at the present day, this being especially the case with regard to kittiwakes, which were once found in thousands where there are now hundreds. So numerous, indeed, were these birds that there is a record of the heaps of twitch left in a field on a Saturday to be carted on the Monday having been carried off in the meantime by the gulls for nest building. The usual ruthless massacres of the old day's were, however, responsible for so reducing the numbers of these birds that they were wellnigh exterminated by the time the Protection Acts once more gave them a chance.

After referring briefly to the puffin and the razorbill, accompanying his notice of the former by an excellent figure of a young bird (herewith reproduced), the author treats in considerable detail of the breeding habits and eggs of the guillemot. Attention is called to the number of young ones and eggs which are destroyed by falling down the cliffs when the birds are suddenly frightened, the author expressing his belief that a guillemot will intentionally roll its egg from the ledge on which it rests if she thinks it is about to be carried off. The remarkable variation displayed by guillemot eggs naturally claims a share of attention, although the author confesses that he is unable to give any reason for the phenomenon. In this connection it may be

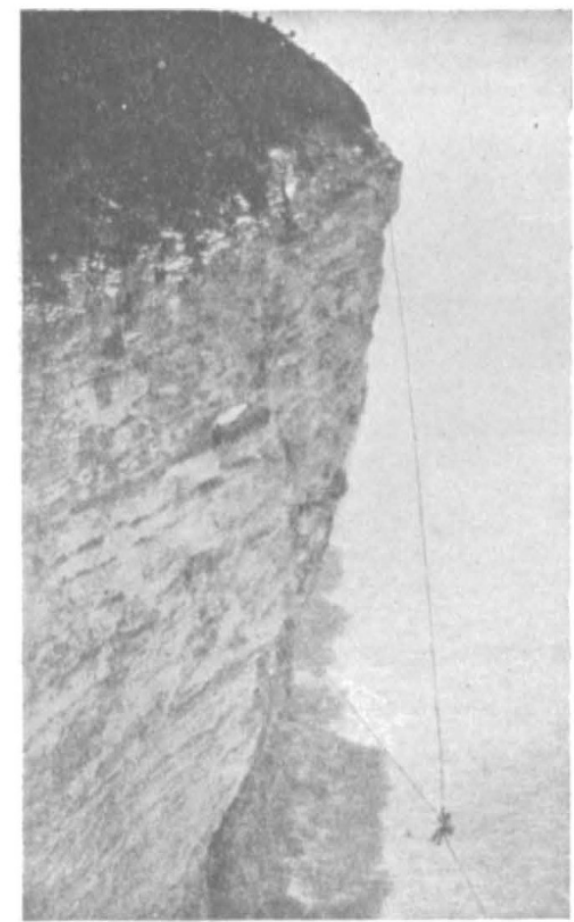

Fig. 2.-A descent in search of eggs. (From the "Birds ut Be upion Cliffs.")

mentioned that a magnificent series of these eggs, showing nearly all the chief types of variation, has recently been placed on exhibition in the Natural History Museum.

Cliff-climbing in Yorkshire is always effected by means of ropes, the author describing it as the most delightful and exciting form of gymnastics. Judging from the illustration here reproduced, some of our readers might think it a trifle too exciting. At the present time from 300 to 400 eggs are collected daily during the season, the total take being about 130,0no. In spite of this drain the numbers of the birds annually increase. The price of the eggs varies from twelve to sixteen a shilling, abnormally marked specimens fetching from $2 d$. to $7 s$. $6 d$., or even more, each. R. L.

\section{A NEW BINOCULAR.}

A NEW form of prismatic binocular, styled the " Service," has recently been issued by Messrs. J. H. Dallmeyer, and there are many interesting features about it for which special advantages may be claimed. As a rule, binoculars consist of two independent optical trains in separate coverings, either hinged together to allow for the different gauges between the separation of human eyes, or made in different sizes to suit these various distances. In the present form the whole optical arrangement is enclosed in one cover, and in consequence of this, six out of the eight prisms employed and the two objective sliding tubes can all be fixed rigidly to one frame, thus ensuring maintenance of adjustment and strength in adverse circumstances.

The separation of the eye-pieces is secured by a screw adjustment situated between them, by which each eye-piece with one prism slides in strong grooves in a lateral direction. For any one individual this adjustment is constant, so that when once the correct position has been attained a permanent mark can be made, and this position quickly regained at any other time; the maximum separation between the centres of the eye-pieces is $70 \mathrm{~mm}$. and the minimum $55 \mathrm{~mm}$., so plenty of latitude is available for abnormal eyes.

There is another screw adjustment for the ordinary focusing, and one of the eye-pieces can be separately adjusted by mearls of a graduated spiral movement in case the observer's eyes are not similar. All these different manipulations can be easily made when only one hand is available, and the whole mechanism can be fully exposed for cleaning the optical surfaces by simply taking out four screws which in no way interfere with any of the adjustments.

Constructed chiefly of magnalium, and in parts of gun-

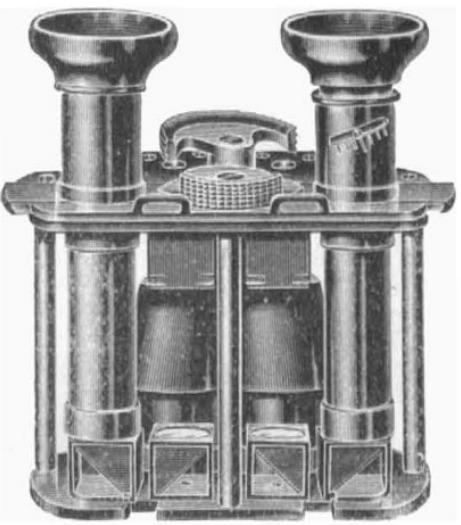

metal, the glasses are light in weight, and it is claimed that they are smaller, power for power, than any other prismatic glass yet made. There are five sizes on the market varying in magnifying power from four to twelve times, the former weighing thirteen and the latter sixteen ounces; the smaller sizes are suitable for theatre or night use.

\section{SEISMOLOGICAL NOTES.}

THE last publication of the Earthquake Investigation Committee of Japan, issued this year, is of special interest to those engaged in seismometry. In it Prof. A. Tanakadate describes a vertical motion seismometer, in which a mass is so suspended that it is not affected by tilting or by horizontal shocks, and remains in neutral equilibrium for vertical displacements of considerable magnitude. Until this instrument was devised, for large earthquakes at least, vertical spring seismographs, and for that matter horizontal bracket seismographs, have responded to the changes in inclination of their supports, with the result that they have

NO. 1742 , voL. 67$]$ 
behaved as clinographs, and components of vertical and horizontal movements have not been faithfully recorded. Mr. Imamura gives results relating to the speeds at which earthquake motion has been propagated over the Tokio area. At four stations, from 2 to 10 kilometres apart, and connected by telegraph, seismographs were arranged each of which gave an open diagram on a surface marked by time intervals sent from the Seismological Institute. From the differences in time at which the same wave was recorded at different stations, the speed of that wave was determined. The surface velocity arrived at is that $\mathrm{V}=3^{\circ} 2 \mathrm{~S}+0^{\circ} 05$ kilometres per second, but as to whether different waves in the same earthquake travel with the same speed, which we think is not the case, we are left in darkness. In a paper on after shocks, Prof. Omori shows that the expected or calculated number of such settlements for a given period closely accords with observation. By maps and diagrams he also shows the space distribution of after shocks, there being, as might be expected, fewer of these disturbances recorded at places distant from a focus than at those conparatively near.

In a paper on pendulum seismographs (Bolletino dell: Societa Sismologia Italiana, vol. vii.) Dr. Agamennone eulogises the work of the Seismological Society of Japan for the revolutionary effect it has had upon seismometry. FCr 130 years prior to the existence of this Society the crdinary instrument employed to record earthquakes was a vertical pendulum. Subsequently horizontal pendulums ivere used, and seismometers took the place of seismoscopes. The results which have been achieved by the new types of instruments as recorders of movements that can be felt are well known, but the value of the records relating to earthqualie motion which has radiated to great distances, beyond timing certain phases of motion, is very doubtful.

The horizontal pendulum largely used in Germany, Austria and Russia, when recording on slowly moving photegraphic paper, has been referred to as a species of delicate seismoscope. To some extent this may be true, but yet it records certain phases of motion, and frequently picks up small disturbances which are not recorded by more cumbrcus forms of apparatus. In his paper Dr. Agamennone gives three seismograms obtained from ordinary pendulums, respectively 16,8 and 3 metres in length, written upon surfaces moving at rates of from 26 to 40 metres per hour. Such seismograms show the earthquake vikrations superimposed upon those due to the swinging of the pendulums. For recording earthquakes at great distances from their origins, Dr. Ömori not only advocates the use of quickly moving surfaces, but that a horizontal type of pendulum should be employed the period of which should be long. On account of the diurnal and other wander-

ings of such a pendulum, for most foundations this period is, however, limited to about thirty seconds.

Other seismologists have also suggestions, and when it is remembered that in a given earthquake continuing for several hours there are groups of waves with periods varying between a fraction of a second and a minute, it is easy to imagine that this should be the case.

In short, so far as the recording of the period and amplitude of unfelt earthquakes are concerned, seismologists are not in step, and until opinions are less divided, which is not likely to be the case until more experiments have been made, to impose a type of instrument upon the world for the purposes specified seems likely to prove detrimental to seismometrical inquiry.

In the last issue of the Bollettino of the Seismological Society of Italy, vol. viii. No. 6, M. Alippi gives a short paper on subterranean sounds. 'The mysterious detonations heard in Holland and on the shores of the North Sea known as mist poeffers are atmospheric phenomena. These, which may be the same as the sounds called barisal guns, must not be confounded with sounds originating in the earth. These latter, which by no means necessarily accompany earthquakes, are in Italy referred to as rombo, bombio, bonniti and other expressions clearly of onomatopoetic origin.

The remaining pages of the number contain the seismic register of Italy for March and April, yor. The late appearance of this register is on account of the fact that it practically includes all observations made upon earthquakes which have been recorded in the Italian peninsula, and as these include world-shaking disturbances, the collection of material from foreign ccuntries occupied considerable time.

As this publication stands facile princeps amongst its kind, Prof. Pietro Tacchini and his staff are to be congratulated on their useful work.

\section{THE NEW BIOLOGICAL STATION AT PORT ERIN.}

THE sixleenth annual report of the Liverpool Marine Biology Committee, ${ }^{1}$ which records the completion and occupation of the new buildings at Purt Erin, opens a fresh period in the history of this Committee, which was constituted in March, i 885 , at a public gathering of the local naturalists from Liverpool, Manchester. Southport, Chester and the neighbour. hood, sumnoned by Prof. Herdman for the purpose. The declared objects were " to investigate the marine fauna and fora (and any related subject such as submarine geology and the

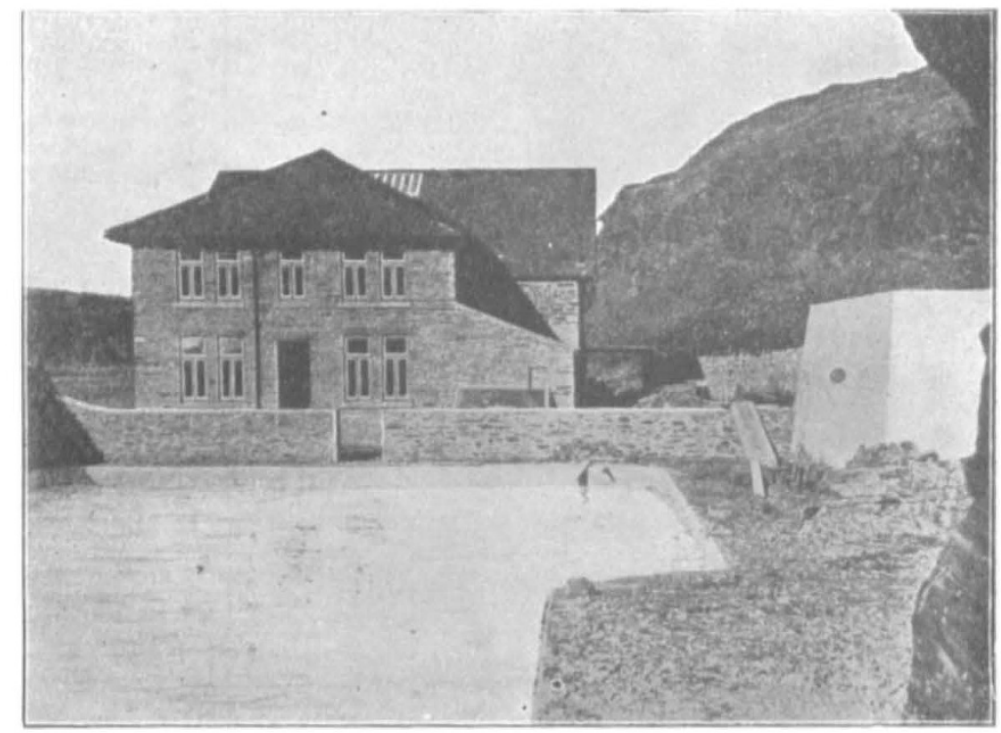

FIG. 1.-Western End of Statisn, showing Spawning Pond and Hatchery Entrance. No. 1742 , vOL. 67]

physical condition of the water) of Liverpool Bay and the neighbouring parts of the Irish Sea, and, if practicable, to establish and maintain a biological station on some convenient part of the coast." These ends have been kept steadily in view for the last seventeen years. At an early stage of the investigations, in 1887 , the Committee established a small biological station on Paffin Island, off the north $c f$ ast of Anglesey, and during the next five years this laboratory was kept up, and dredging and other exploring expeditions were carried on from it.

Then the centre of the Committee's field work was transferred from Anglesey to the Isle of Man-" from the Mona of Tacitus to the Mona of Cæsar." Here a small biological station was built on the northern side of Port Erin Bay and was formally opened for work on June 4, 1892, by Sir Spencer Walpole, then Governor of the island. Notices of the work carried on in this laboratory and of the dredging expeditions in the Irish Sea 